\title{
Correction to: Incorporating citizen science, museum specimens, and field work into the assessment of extinction risk of the American Bumble bee (Bombus pensylvanicus De Geer 1773) in Canada
}

\author{
Victoria J. MacPhail ${ }^{1}\left[\right.$. Leif L. Richardson ${ }^{2} \cdot$ Sheila R. Colla \\ Published online: 22 May 2019 \\ ๑) Springer Nature Switzerland AG 2019

\section{Correction to: Journal of Insect Conservation https://doi.org/10.1007/s10841-019-00152-y}

In the original publication of the article, the Acknowledgments information was missed. It is provided below.

Acknowledgements We thank all museum collections and contributors of bumble bee species occurrence data to the Bumble Bees of North America database managed by LLR (see http://www.leifrichardson.org/bbna.html). We thank everyone who submitted and/or verified observations for the citizen science program Bumble Bee Watch, especially Rich Hatfield of the Xerces Society, and to the partners and funders of that program. We thank Environment and Climate Change Canada, the Ontario Ministry of Natural Resources and Forestry, The W. Garfield Weston Foundation, the Rogers Foundation, the Schad Foundation, and Wildlife Preservation Canada for funding and supporting the field research by VJM and SRC. We acknowledge the support of the Natural Sciences and Engineering Research Council of Canada (NSERC), reference numbers RGPIN-2017-05642 and CGSD-503997-2017. VJM also thanks the rare Charitable Research Preserve for a scholarship.

The original article can be found online at https://doi.org/10.1007/ s10841-019-00152-y.

Victoria J. MacPhail

macphail@yorku.ca

1 Faculty of Environmental Studies, York University, Toronto, ON, Canada

2 Gund Institute for Environment, Rubenstein School of Environment and Natural Resources, University of Vermont, Burlington, VT, USA
Publisher's Note Springer Nature remains neutral with regard to jurisdictional claims in published maps and institutional affiliations. 